\title{
Further evidence for genetic anticipation in familial rheumatoid arthritis
}

\author{
Elizabeth McDermott, Muhammad Asim Khan, ARC UK National Repository, \\ Chris Deighton
}

\begin{abstract}
Objective-To determine whether preliminary evidence supporting features of genetic anticipation in familial rheumatoid arthritis (RA) could be replicated in independent and larger samples.

Method-Data were obtained from records of 59 multicase families from the Arthritis and Rheumatism Council (ARC) National Repository in Manchester, 65 multicase families from Cleveland, Ohio, USA, and 253 consecutive patients with $R A$ attending clinics in Nottingham.

Results-Mean ages of disease onset in the parents affected with RA were consistently greater than those in the probands. In the ARC data, the mean age difference in disease onset between the affected mother and proband pairs was 16.0 years $(95 \%$ confidence interval (CI) 7.2 to 24.8 years, $n=11$ ); in the Cleveland data it was $7 \cdot 8$ years $(95 \%$ CI 0.9 to $14 \cdot 7$ years, $n=24)$, and in the Nottingham data it was $10 \cdot 4$ years $(95 \%$ CI $2 \cdot 8$ to $18 \cdot 0$ years, $n=28)$. Similar results were found in the limited number of father-proband pairs. Unlike the findings of earlier work, there was no correlation between proband age at disease onset and age of the parent at conception of the proband.

Conclusion-In independent and larger familial RA data sets, features of genetic anticipation were replicated. Our findings support the case for further research at a molecular level into genetic anticipation in those families with two successive generations affected by RA.
\end{abstract}

(Ann Rheum Dis 1996; 55: 475-477)

Genetic anticipation is the term applied to the tendency for diseases to become more severe and to develop at earlier ages in each subsequent generation. In the past five years, unstable expanded trinucleotide repeat sequences have been demonstrated for some diseases that demonstrate genetic anticipation. ${ }^{1-3}$ The increasing length of the triplet repeat sequence correlates with decreasing age of disease onset and increasing disease severity. Examples include myotonic dystrophy, fragile $\mathrm{X}$, Huntington's disease, spinal and bulbar muscular atrophy, and spinocerebellar ataxia. ${ }^{4}$ Features consistent with genetic anticipation have recently been described in complex genetic diseases such as schizophrenia, ${ }^{5}$ bipolar affective disorder, ${ }^{6}$ and osteoarthritis (Regan M, Deighton CM, Doherty M; submitted for publication).

A preliminary study published in 1994 presented evidence suggesting that genetic anticipation may occur in familial rheumatoid arthritis (RA). ${ }^{7}$ Data were obtained from 15 affected parent-offspring pairs from multicase families in Newcastle (seven mother-proband pairs), and from 153 consecutive outpatients with rheumatoid arthritis (RA) (20 motherproband pairs). Comparisons of age of onset between the affected mothers and probands showed earlier ages of onset in the probands in both data sets. In the maternal RA group, both the maternal and paternal age at proband conception showed significant negative correlations with the age of disease onset in the proband. In the seven affected pairs from the muliticase pedigrees, the probands had a tendency to more severe disease, despite shorter disease duration and younger age. The aim of the present study was to determine whether some of these features could be reproduced in larger and independent data sets.

\section{Subjects and methods}

Data were collected from independent sources. The Arthritis and Rheumatism Council (ARC) National Repository of RA pedigrees provided 59 multicase families; ${ }^{8} 65$ multicase families were studied in the United States. ${ }^{9}$ All these cases had been examined and investigated by a physician or metrologist trained in assessing $\mathrm{RA}$; the Cleveland probands fulfilled the 1958 American Rheumatism Association (ARA) criteria for definite or classical $\mathrm{RA},{ }^{10}$ and the ARC probands fulfilled the modified 1987 ARA criteria. ${ }^{8}$ Dates of birth and ages of symptomatic onset of disease were recorded in all affected cases. Two hundred and fifty three consecutive outpatients with RA who fulfilled the 1987 ARA criteria were identified from the Nottingham rheumatology clinics. Age of onset in the proband and disease status (based on the 1987 ARA criteria) ${ }^{11}$ were ascertained from the medical notes and those of the parent were obtained from either the medical notes or proband interview.

\section{STATISTICAL ANALYSIS}

The mean age of onset was calculated for: all probands; probands with affected mothers; 
Comparison of mean ages of onset and mean age differences in each data set

\begin{tabular}{|c|c|c|}
\hline & Age of onset (yr) & $\begin{array}{l}\text { Difference in } \\
\text { age of onset (yr) }\end{array}$ \\
\hline $\begin{array}{l}\text { ARC data set } \\
\text { All probands }(n=59) \\
\text { Probands with RA mothers }(n=11) \\
\text { RA mothers }(n=11) \\
\text { Probands with RA fathers }(n=9) \\
\text { RA fathers }(n=9) \\
\text { Mother-proband pairs } \\
\text { Father-proband pairs }\end{array}$ & $\begin{array}{l}28.6(26.2 \text { to } 31 \cdot 1) \\
27.7(22.8 \text { to } 32.7) \\
43.7(34.9 \text { to } 52.5) \\
27.0(20.3 \text { to } 33.7) \\
48.2(38.6 \text { to } 57.9)\end{array}$ & $\begin{array}{l}16.0(7.2 \text { to } 24 \cdot 8) \\
21.2(10.6 \text { to } 31 \cdot 8)\end{array}$ \\
\hline $\begin{array}{l}\text { United States data set } \\
\text { Probands }(n=115) \\
\text { Probands with RA mothers }(n=24) \\
\text { RA mothers }(n=24) \\
\text { Probands with RA fathers }(n=9) \\
\text { RA fathers }(n=9) \\
\text { Mother-proband pairs } \\
\text { Father-proband pairs }\end{array}$ & $\begin{array}{l}39 \cdot 3(36 \cdot 8 \text { to } 41 \cdot 8) \\
35.8(30.3 \text { to } 41 \cdot 2) \\
43.6(37.2 \text { to } 49.9) \\
39.2(33.0 \text { to } 45 \cdot 4) \\
42.8(36.4 \text { to } 49 \cdot 2)\end{array}$ & $\begin{array}{l}7.8(0.9 \text { to } 14.7) \\
3.6(-6.0 \text { to } 13.2)\end{array}$ \\
\hline $\begin{array}{l}\text { Nottingham data set } \\
\text { All probands }(n=253) \\
\text { Probands with RA mothers }(n=28) \\
\text { RA mothers }(n=28) \\
\text { Probands with RA fathers }(n=21) \\
\text { RA fathers }\left(n=16^{\star}\right) \\
\text { Mother-proband pairs } \\
\text { Father-proband pairs }\end{array}$ & $\begin{array}{l}44.5(42.8 \text { to } 46 \cdot 2) \\
43.1(37.8 \text { to } 48 \cdot 4) \\
53.5(46.8 \text { to } 60.2) \\
44.9(40 \cdot 1 \text { to } 49 \cdot 6) \\
51.0(43.9 \text { to } 58 \cdot 1)\end{array}$ & $\begin{array}{c}10 \cdot 4(2 \cdot 8 \text { to } 18 \cdot 0) \\
6 \cdot 1(-2 \cdot 7 \text { to } 14.9)\end{array}$ \\
\hline
\end{tabular}

Values are mean ( $95 \%$ confidence interval).

*Age of onset unknown in five fathers.

affected mothers; probands with affected fathers; affected fathers.

We calculated the $95 \%$ confidence intervals for the mean differences in age of onset between parent-proband pairs.

Correlation coefficients were calculated for age of disease onset in the proband and age of the parent at conception of the proband.

\section{Results}

The mean ages of disease onset in the probands, affected mothers, and fathers were similar in all data sets (table). However, the ARC probands developed symptomatic RA at an earlier age than cases in the other data sets. As would be expected from the sex distribution of RA, there were fewer father-proband pairs than mother-proband pairs. In all data sets in which families with two successive generations were affected, parents tended to experience start of their disease at a later age than their affected offspring. Significant results were found in all the affected mother-proband pairs and in the ARC affected father-proband pairs. Comparing differences between motherdaughter and mother-son pairs was difficult because of the small numbers of mother-son pairs (two in the ARC data set, eight in the USA data set, and nine in the Nottingham data set). We found no correlation between age of disease onset in the proband and age of the parent at conception of the proband in any of the data sets.

\section{Discussion}

In all data sets the affected mothers developed the disease at an older age than the probands. Fathers also tended to start with disease at an older age than the probands, though only the ARC results were statistically significant. These results are consistent with genetic anticipation and are in keeping with our previous findings. ${ }^{7}$ However, our preliminary study showed negative correlation between the parent's age at conception of the offspring and the offspring's age at disease onset in the mother-proband pairs. We found no such correlation in any of the current data sets. A negative correlation has been shown for paternal age at conception of the offspring and age of onset of myotonic dystrophy and Huntington's chorea in the offspring, but this analysis required large numbers of families. ${ }^{12}$ Instability of germline mitotic divisions throughout the lifetime of the father is one mechanism that has been suggested. ${ }^{12} 13$ It seems likely that, in RA, parental ages at conception of the offspring have either no, or a very weak, effect on proband age at onset of disease. Whilst this weakens the case for genetic anticipation, it does not exclude it.

Epidemiological studies of disease that search for evidence of genetic anticipation are prone to bias, as has been argued through this century. Penrose described the main bias, suggesting that pedigrees in which the proband developed the disease at an early age and the parent developed the disease much later in life, were much more likely to be identified than pairs in which the reverse was true. ${ }^{1}$ Offspring of affected parents are likely to be more aware of the disease and hence report symptoms sooner. Recall bias is another consideration, as older patients may forget early symptoms and remember disease onset occurring later than it actually did. Whilst we cannot exclude these biases, we have made similar observations in all three independent populations. A cohort effect is unlikely because, if anything, RA is becoming less common and less severe, which tends to work against the concept of genetic anticipation. $^{7}$

In this study we took onset of symptoms as our definition of disease onset. In patients with an insidious disease onset, defining when the disease starts may be difficult. At present we have no better method than recording the patient's first recollection of significant symptoms. This problem will be present in both parent and proband groups and can be considered a random bias. One way to assess this effect would be to compare the age of onset differences in parent-offspring pairs experiencing an explosive disease onset with that in those having a more insidious or palindromic disease onset. We were unable to do this in our study as numbers were too small.

There was some disparity between the results from the three populations. Principally, there was an earlier age of onset in the probands from the ARC data set. This observation could simply be a bias of ascertainment arising from the requirement by the ARC to find two affected siblings with both parents still alive. There is no epidemiological evidence at present that suggests familial RA starts earlier than non-familial disease. ${ }^{14}$ The features of genetic anticipation are only demonstrable in a subset of patients with RA, as most cases are not familial. From the Nottingham data, only $19 \%$ of probands reported a parent or offspring as also being affected. 
In conclusion, the presence of features consistent with genetic anticipation in familial $\mathrm{RA}$ is an interesting finding and adds weight to the previous study. ${ }^{7}$ Already, searches for expanded trinucleotide repeats are taking place in many other familial multifactorial diseases using the 'Repeat Expansion Detection' system. This procedure searches genomic DNA without requiring prior knowledge of the expected site of the repeat. ${ }^{15}$ We believe that the evidence for genetic anticipation in familial RA warrants investigations on a molecular level.

1 Harper P S, Harley H G, Reardon W, Shaw D J. Anticipation in myotonic dystrophy: new light on an old problem. Am $\mathfrak{f}$ Hum Genet 1992; 51: $10-6$.

2 Richards R I, Sutherland G R. Heritable unstable DNA sequences. Nature Genet 1992; 1: 7-9.

3 Caskey C T, Pizzuti A, Fu Y H, Fenwick R G, Nelson D L. Triplet repeat mutations in human disease. Science 1992;
taskey C T, Pizzuti A, Fu Y H, Fenwick R G, Nelson D L. 256: 784-9.

4 Ranum L P W, Chung M, Banfi S, et al. Molecular and clinical correlations in spinocerebellar ataxia type 1: evidence for familial effects on age at onset. Am $\mathcal{f}$ Hum Genet 1994; 55: 244-52.
5 Bassett A S, Honer W G. Evidence for anticipation in schizophrenia. Am f Hum Genet 1994; 54: 864-70.

6 Ross C A, McInnis M G, Margolis R L, Li S H. Genes with triplet repeats: candidate mediators of neuropsychiatric disorders. Trends Neurosci 1993; 16: 254-60.

7 Deighton C M, Heslop P, McDonagh J, Walker D J, Thomson G. Does genetic anticipation occur in rheumatoid arthritis? Ann Rheum Dis 1994; 53: 833-5.

8 Worthington J, Ollier W E R, Leach M K, et al. The Arthritis and Rheumatism Council's National Repository of family material: pedigrees from the first 100 rheumatoid arthritis 1994; 33: 970-6.

9 Yamashita T S, Khan M A, Kushner I. Genetic analysis of families with multiple cases of rheumatoid arthritis. Dis Markers 1986; 4: 113-21.

10 Ropes M W, Bennett G A, Cobb S, Jacox R, Jessar R A. 1958 Revision of diagnostic criteria for rheumatoid arthritis. Bull Rheum Dis 1958; 9: 175-6.

11 Arnett F C, Edworthy S M, Bloch D A, et al. The American Rheumatism Association 1987 revised criteria for the classification of rheumatoid arthritis. Arthritis Rheum 1988; 31: 315-24.

12 Zheng C-J, Byers B, Moolgavkar S H. Allelic instability in mitosis: a unified model for dominant disorders. Proc Natl Acad Sci USA 1993; 90: 10178-82.

13 Deighton C M, Thomson G. Genetic anticipation and musculoskeletal disease. Ann Rheum Dis 1994; 53: musculos.

14 Deighton C M, Walker D J. The familial nature of theumatoid arthritis. Ann Rheum Dis 1991; 50: 62-5.

15 Schalling M, Hudson T J, Buetow K H, Housman D E. Direct detection of novel expanded trinucleotide repeats in the human genome. Nature Genet 1993; 4: 135-9. 